\title{
A Educação Especial como um dos direitos humanos: contextualização fática das políticas educacionais
}

\section{Special Education as a human rights: factual context of educational policies}

\author{
La Educación Especial como uno de los derechos \\ humanos: contextualización fática de las políticas \\ educativos
}

Nadia Bigarella ${ }^{1}$ Alessandro Gomes Lewandowski ${ }^{2}$ Janine Azevedo Barthimann Carvalho ${ }^{3}$

${ }^{1}$ Doutorado em Educação - Universidade Católica Dom Bosco (UCDB). Mestrado em Educação - Universidade Federal de Mato Grosso do Sul, especialização em Didática Universitária - UCDB. Especialização Língua Portuguesa e Literatura- Universidade para o Desenvolvimento do Estado do Pantanal. Graduação em Pedagogia - Faculdades Unidas Católicas de Mato Grosso. Professora do Programa de Pós-Graduação - Mestrado e Doutorado da UCDB, ligada à Linha de Pesquisa Políticas Educacionais em Educação Gestão da Escola

e Formação Docente e ao Grupo de Pesquisa Políticas Públicas e Gestão da Educação (GEPPE). Professora das disciplinas Didática I e História da Educação, do Curso de Pedagogia da UCDB. Atua principalmente nos seguintes temas: conselhos de educação, gestão e políticas públicas educacionais e gestão educacional da educação básica. E-mail: nadiabiga@hotmail.com

${ }^{2}$ Mestrando do Programa de Pós-Graduação em Educação Mestrado e Doutorado da Universidade Católica Dom Bosco (UCDB).

E-mail: advaglew@gmail.com

${ }^{3}$ Mestranda do Programa de Pós-Graduação em Educação Mestrado e Doutorado da Universidade Católica Dom Bosco (UCDB). E-mail: janbarthimann@hotmail.com 
Resumo: Este artigo é decorrente de duas pesquisas de mestrado em andamento, que investigam o Plano Estadual de Educação do Estado de Mato Grosso do Sul (2014-2024), em dois aspectos: a educação como direito humano e a educação especial na educação básica. Tem por objetivo fazer uma reflexão das políticas de educação especial no Brasil e a aplicabilidade do direito à educação, como ação imprescindível para universalizar e educação para pessoas com deficiência. Com base em pesquisas documentais, parte dos princípios educacionais prescritos na Constituição Federal em 1988 e Lei de Diretrizes e Bases Nacional 9.394/1996. O caráter reflexivo do estudo evidencia que o direito à educação, para atingir a verdadeira finalidade do Poder Constituinte Originário, tem que criar mecanismos de proteção da cidadania, condição sine qua non para a materialização do direito à educação básica e ao atendimento educacional especializado, pois, sem os direitos educacionais reconhecidos, protegidos, não há cidadania nem possibilidade de se construir uma sociedade constituída por cidadãos emancipados e independentes.

Palavras-chave: direito à educação; educação como direito humano; Educação Especial.

Abstract: This article is part of two ongoing Masters researches, investigating the Education State Plan (2014-2024) of the State of Mato Grosso do Sul, in two respects: education as a human right and special education in basic education. It aims to make a reflection of the special education policy in Brazil and the applicability of the right to education as an essential action to universalize the education for people with disabilities, 4-17 years. Based on documental research, part of the educational principles prescribed in the Federal Constitution of 1988 and Guidelines and Bases Law 9.394/1996. The reflective character of the study shows that the right to education, to achieve the true purpose of the Original Constituent Power, have to create protective mechanisms of citizenship, sine qua non condition for the materialization of the right to basic education and specialized education, because, without recognized educational rights, protected, there is no citizenship neither a possibility of building a society consists of emancipated and independent citizens.

Key words: right to education; education as a human right; Special Education.

Resumen: Este artículo es el resultado de dos estudios de maestría en curso, que investigan el Plan Estatal de Educación del Estado de Mato Grosso del Sur (2014-2024) en dos aspectos: la educación como un derecho humano y la educación especial en la educación básica. Su objetivo es reflejar la política de educación especial en Brasil y la aplicabilidad del derecho a la educación, como una acción esencial para universalizar y educación para las personas con discapacidades 4-17 años. Basado en una investigación documental, que forma parte de los principios educativos prescritos en la Constitución en 1988 y las Directrices de la Ley y de Bases de Datos Nacionales 9.394/1996. El carácter reflexivo del estudio muestra que el derecho a la educación, para lograr el verdadero propósito del poder constituyente originaria, tiene que crear mecanismos de protección de la ciudadanía, una condición sine qua non para la realización del derecho a la educación básica y la educación especializada, sin derechos educativos reconocidos protegidas, no hay ciudadanía o posibilidad de construir una sociedad se compone de ciudadanos emancipados e independientes.

Palabras clave: derecho a la educación, la educación como un derecho humano, la Educación Especial. 


\section{INTRODUÇÃO}

Estudar a educação como direito humano, significa entendê-lo como um produto histórico dos movimentos que reagiram às desigualdades sociais, refletidas nas políticas que, muitas vezes, impedem ao trabalhador a superação de classe social, muitas vezes atingida pela atuação e/ou pela omissão do Estado na oferta de serviços que, por lei, são de sua responsabilidade e direito dos cidadãos.

Dessa forma, a ideia da educação como serviço público, gratuito, de qualidade e socialmente referenciado, deriva das lutas travadas entre classes sociais em diferentes contextos históricos. Logo, para discutir a aplicabilidade do direito à educação, como ação imprescindível para universalizar e educação para pessoas com deficiência, precisamos considerar a afinidade entre educação e democracia, uma vez que a educação é mediadora da construção do conceito coletivo de democracia, de sujeitos agentes de transformação (ou de reprodução) da vida coletiva, das ideias de justiça social, de participação e de defesa (ou não) de direitos políticos e sociais, compartilhadas com a totalidade da sociedade.

Como os conceitos de direito, democracia, coletividade e participação são influenciados pelos valores presentes em uma sociedade liberal produtiva, são polissêmicos e/ou multifacetados, pois, quase sempre, tendem a adotar diferentes significados, conforme a conjuntura e os fundamentos normativos internacionais e as necessidades locais. Dizendo isso de outra forma, esses conceitos, sempre, vão expressar um entendimento de democracia, articulada com um projeto de sociedade que se está buscando implantar, por meio de ações, planos, programas e projetos políticos, consignando assim, as crenças, interesses e concepção de mundo, de sociedade e de cidadão.

Esses planos, projetos e programas, são documentos que trazem ações políticas para contextos local ou nacional. Como o Brasil 
é um dos países signatários do Pacto Internacional sobre Direitos Econômicos, Sociais e Culturais, desde 1966, deve reconhecer o direito de toda pessoa à educação e deve fortalecer o respeito aos direitos humanos e as liberdades fundamentais. Por isso, este texto envolve mais que a normatização a respeito desse direito, envolve fatos históricos, normas e sua validade, transformações no pensamento e sentimento humano, correlação de forças e a necessidade de vencer as forças hegemônicas, conservadoras, capitalistas, que determinam o tipo de sociedade em que devemos viver. Busca assim, fazer uma relação do geral para o particular, para compreender não só a si mesmo, mas compreender as outras atividades humanas que influenciaram os conceitos de direito à educação como um dos direitos humanos e sua trajetória pela história.

Para tanto, parte-se do princípio de que o direito à educação é de todos e não se refere somente à educação escolar, refere-se à vida, pois esse processo tem início com o nascimento e somente se encerra com morte. Esse processo ocorre em múltiplos campos: na família, na comunidade, na igreja, na associação, nos sindicatos, no trabalho, no grupo social e na escola, lugar escolhido pelas sociedades moderna e contemporânea, de acesso ao conhecimento acumulado pela humanidade. Desse modo, a educação ajuda as pessoas a entenderem o mundo e construírem uma vida melhor, por meio da inclusão no mundo do trabalho, pela participação política, na medida em que têm conhecimento de seus direitos sociais e de seu papel de cidadão.

\section{DIREITO À EDUCAÇÃO EM DIVERSOS CONTEXTOS HUMANOS}

A história mostra que a preocupação com o direito à educação perpassou pela Revolução Francesa (1789-1799), momento em que a burguesia se mostra como classe revolucionária e conquista o poder, e trouxe a ideia de democracia, liberdade e da educação como direito, 
conforme apresenta a análise de Saviani (1997, p. 17-18):

O direito à educação decorria do tipo de sociedade correspondente aos interesses da nova classe que consolidara no poder: a burguesia. Tratava-se, pois, de construir uma sociedade democrática, de consolidar a democracia burguesa. Para superar a situação de opressão própria do "Antigo Regime", e ascender a um tipo de sociedade fundada no contrato social celebrado "livremente" entre os indivíduos, era necessário vencer a barreira da ignorância. Só assim seria possível transformar os súditos em cidadãos, isto é, em indivíduos livres porque esclarecidos, ilustrados.

Em consequências das ideias de liberdade, igualdade e fraternidade, difundidas na Revolução Francesa, em 1793, houve a Declaração dos Direitos do Homem e do Cidadão, originário da Convenção Nacional Francesa, em especial, o artigo 22, aduzindo que "[...] a instrução é a necessidade de todos. A sociedade deve favorecer com todo o seu poder o progresso da inteligência pública e colocar a instrução ao alcance de todos os cidadãos", o que desde já nos aponta para uma visão do direito à educação como um direito do homem, ou seja, um direito natural, resguardado pelo direito internacional, o que desencadeará conclusões com a evolução do artigo (BRASIL, 2013).

Esses princípios, que desde a Revolução Francesa (1789-1799) tornaram-se os pilares da sociedade moderna, os Direitos Humanos, foram transformados em mecanismo de combate às situações de desigualdades, de acesso aos bens materiais e/ ou imateriais, as

[...] discriminações praticadas sobre as diversidades socioculturais, de identidade de gênero, de etnia, de raça, de orientação sexual, de deficiências, dentre outras e, de modo geral, as opressões vinculadas ao controle do poder por minorias sociais. (BRASIL, CNE/CP, 2012, p. 3).

No Brasil, diferente da Europa, a educação teve início na colonização, então pautada pelas ideias Jesuítas, de caráter seletivo, para 
poucos, cabendo às famílias da elite o direito à educação e tendo como objeto o que o mercado necessitava. Em 1824, foi promulgada a primeira Constituição do Brasil, a Constituição Imperial, a mais longa na história do nosso País, sendo que a educação foi tratada no artigo 179, em especial inciso XXXII ${ }^{1}$, aduzindo direitos aos brasileiros quanto à instrução primária, sendo gratuita a todos os cidadãos, bem como, no inciso XXXIII², previu a criação de colégios e universidades (BIGARELLA, 2015).

Em 1969, pela Emenda Constitucional № 1, a educação foi normatizada como um dever do Estado, em especial no artigo 176, aduzindo que "A educação, inspirada no princípio da unidade nacional e nos ideais de liberdade e solidariedade humana, é direito de todos e dever do Estado, e será dada no lar e na escola", contudo, sem a devida efetividade (BRASIL, 1969).

Na década de 1970, a concentração das decisões políticas e administrativas acontecia na esfera federal, contudo, frente à crise nacional, passando para modelo neoliberal, o Estado brasileiro buscou descentralizar a sua administração para torná-la mais barata e criar novas formas de relacionamento com a sociedade civil, que estão relacionadas, e muito reproduz, segundo Hobsbawn (1995), Mészáros (2008), Ianni (1997), a lógica mercantil-capitalista.

Por conseguinte, a educação é, antes de tudo, um direito individual, uma garantia do cidadão, assegurada pelo Estado, ou seja, o fato de ser assegurada não significa que surgiu com o Estado, mas sim

\footnotetext{
${ }^{1}$ Art. 179. A inviolabilidade dos Direitos Civis, e Politicos dos Cidadãos Brazileiros, que tem por base a liberdade, a segurança individual, e a propriedade, é garantida pela Constituição do Imperio, pela maneira seguinte, XXXII. A Instrucção primaria, e gratuita a todos os Cidadãos. Disponível em: <http://www.planalto.gov.br/ccivil_03/ Constituicao/Constituicao24.htm>. Acesso em: 23 abr. 2016.

${ }^{2}$ XXXIII. Collegios, e Universidades, aonde serão ensinados os elementos das Sciencias, Bellas Letras, e Artes. Disponível em: <http://www.planalto.gov.br/ccivil_ 03/Constituicao/Constituicao24.htm>. Acesso em: 23 abr. 2016.
} 
que existe desde os primórdios, cabendo ao Estado apenas efetivar a proteção, bem como a máxima implementação. Frente à existência da problemática da educação, indubitável o entendimento e a divisão do que vem a ser direitos humanos, direito do homem e direitos fundamentais, socorrendo-se, assim, aos ensinamentos de Sarlet (2007, p. 36), que explica as concepções de

[...] 'direitos do homem' (no sentido de direitos naturais não, ou ainda não positivados), 'direitos humanos' (positivados na esfera do direito internacional) e 'direitos fundamentais' (direitos reconhecidos ou outorgados e protegidos pelo direito constitucional interno de cada Estado).

A Carta da Organização das Nações Unidas de 1945, o primeiro instrumento jurídico internacional a proclamar o valor universal dos "direitos do homem", incluindo nesta análise a educação, seguido pela Declaração Universal dos Direitos do Homem em 1948, aduz o direito à educação, além dos direitos de cidadania, mas também como um direito humano, tendo, assim, sua origem, sua base, no direito natural, logo vindo antes de qualquer positivação estatal (BRASIL, 2013).

E, ainda, a educação, como direito universal, está vinculada ao conceito de cidadania, encartada no artigo 1이 II, da Constituição Federal de 1988. A cidadania é exercício dos direitos e dos deveres constitucionais. A garantia dos direitos sociais é uma etapa da conquista dos direitos de cidadania. Somado a isso, o capítulo II, que aduz ao artigo 6ㅇ da CF (direito à educação), está inserido no título II (dos direitos e garantias fundamentais); logo, a educação é um direito fundamental e, ainda, merece a proteção do artigo 60, §4으, IV ${ }^{3}$, da CF, ou seja, é uma cláusula pétrea, impossibilitando sua retirada pelos governos presentes e futuros (BRASIL, 1998).

\footnotetext{
${ }^{3}$ Art. 60. A Constituição poderá ser emendada mediante proposta:

§ 4 ㅇ Não será objeto de deliberação a proposta de emenda tendente a abolir:

IV- os direitos e garantias individuais.
} 
Frente a tais considerações, fica patente que o direito à educação é um direito público subjetivo, conforme pontuado no $\S 1$ 으 do artigo 208 da CF/1988 ${ }^{4}$. Assim, presume-se que a garantia desse direito presente na Lei Maior, configura-se uma relação jurídica: tendo de um lado, o Estado (atendendo sua missão quanto à aplicação de um direito de segunda geração/dimensão), que tem o dever jurídico com a educação, e de outro, o indivíduo, que tem o direito público subjetivo de exigir o cumprimento da obrigação educacional por parte do poder público (BRASIL, 1998). Esse direito traz consequências para o Estado Democrático de Direito, uma vez que terá que fazer valer, conforme discussão apresentada anteriormente, os princípios da igualdade, gratuidade, democracia e qualidade social para todos, o que implica o dever do Estado em garantir atendimento educacional especializado na rede regular de ensino, muito embora, existam pensamentos que vêm, ao longo da história, contrários aos do Estado Democrático de Direito, que defendem que o atendimento às crianças com deficiência deve acontecer exclusivamente em escolas especiais, fechando, assim, todas as possibilidades das redes convencionais se prepararem para receber todos alunos, conforme a discussão apresentada na próxima seção.

\section{DIREITO À EDUCAÇÃO E A POLÍTICA EDUCACIONAL PARA A EDUCAÇÃO ESPECIAL}

Na década de 1990, um movimento nacional, como também internacional, liderados pelos organismos internacionais eram caracterizados pelo discurso da educação para todos, especialmente, a Conferência Mundial de Educação para Todos, realizada em Jontiem, na Tailândia, em 1990, e a Conferência Mundial sobre Necessidades Educacionais Especiais, realizada, em 1994, em Salamanca. Isso

\footnotetext{
${ }^{4}$ Art. 208. O dever do Estado com a educação será efetivado mediante a garantia de: $\S 1$ o 0 acesso ao ensino obrigatório e gratuito é direito público subjetivo.
} 
reavivou a cobrança da sociedade para que o Estado assumisse a sua responsabilidade pelo direito educacional das pessoas com necessidades especiais, que historicamente estiveram segregadas das escolas regulares e confinadas nas escolas especializadas, sem a possibilidade de conviverem, participarem e aprenderem junto com outras crianças que estudavam nas escolas regulares (BRASIL, 1994).

Nesse sentido, as duas conferências registraram a defesa das pessoas com necessidades especiais em duas declarações: a Declaração Mundial sobre Educação para Todos: satisfação das necessidades básicas de aprendizagem, e a Declaração de Salamanca (1994). Essas duas declarações, de acordo com Machado e Vernick (2013), influenciaram a retirada do termo excepcional dos documentos oficiais, substituindo-o por pessoas com deficiência, conforme os padrões internacionais.

A substituição do termo, conforme explica Sassaki (2003), reside no fato de compatibilizar terminologia com os valores vigentes naquele momento histórico, assim demarcando a evolução e preocupação do Estado em imprimir outras bases para o relacionamento com as pessoas com deficiência, pois a construção de um modelo de sociedade mais justa, menos excludente, passa também, de acordo com o mesmo autor, pelo cuidado com a linguagem, que expressa (consciente ou inconsciente) o respeito ou a discriminação em relação às pessoas com deficiências.

Mas, com relação à educação especial, essas duas Declarações reiteraram o que promulgou a Constituição Federal (CF/1988) no Art. 3 o, inciso IV, constituído como um dos objetivos fundamentais da República Federativa do Brasil: "promover o bem de todos, sem preconceitos de origem, raça, sexo, cor, idade e quaisquer outras formas de discriminação" (BRASIL, 1988). Esse objetivo se entrelaça com proposta de educação inclusiva, expressa no Art. 208, inciso II, que se refere ao "[...] atendimento educacional especializado aos portadores de 
deficiência, preferencialmente na rede regular de ensino", definida pela primeira vez na história como modalidade de ensino (BRASIL, 1988).

A Lei de Diretrizes e Bases da Educação Nacional (LDBEN) 9.394/1996, Art. 58, alterada pela Lei no 12.796/2013, conceitua educação especial, para os efeitos da Lei, como uma modalidade de educação escolar, que engloba pessoas com necessidades especiais e superdotadas, que devem ser atendidas preferencialmente na rede regular de ensino (BRASIL, 1996). Para Kassar (2011), Garcia e Michels (2011) a LDBEN/1996 propôs um satisfatório atendimento às pessoas com deficiência e, assim, trouxe para o debate o discurso de inclusão escolar.

O artigo 59 apresenta um conjunto de dispositivos referentes aos serviços que devem ser prestados pelo poder público:

I- Currículos, métodos, técnicas, recursos educativos e organização específicos, para atender às suas necessidades;

II - Terminalidade específica para aqueles que não puderem atingir o nível exigido para a conclusão do ensino fundamental, em virtude de suas deficiências, e aceleração para concluir em menor tempo o programa escolar para os superdotados;

III- professores com especialização adequada em nível médio ou superior, para atendimento especializado, bem como professores do ensino regular capacitados para a integração desses educandos nas classes comuns;

IV- Educação especial para o trabalho, visando a sua efetiva integração na vida em sociedade, inclusive condições adequadas para os que não revelarem capacidade de inserção no trabaIho competitivo, mediante articulação com os órgãos oficiais afins, bem como para aqueles que apresentam uma habilidade superior nas áreas artística, intelectual ou psicomotora;

V - Acesso igualitário aos benefícios dos programas sociais suplementares disponíveis para o respectivo nível do ensino regular. (BRASIL, 1988). 
A Resolução CNE/CEB no 02, de 11 de setembro de 2001, que institui as Diretrizes Nacionais para a Educação Especial na Educação Básica, esclareceu quem são as pessoas consideradas com necessidades educacionais especiais:

Art. 5o Consideram-se educandos com necessidades educacionais especiais os que, durante o processo educacional, apresentarem:

I- dificuldades acentuadas de aprendizagem ou limitações no processo de desenvolvimento que dificultem o acompanhamento das atividades curriculares, compreendidas em dois grupos:

a) aquelas não vinculadas a uma causa orgânica específica

b) aquelas relacionadas a condições, disfunções, limitações ou deficiências;

II - dificuldades de comunicação e sinalização diferenciadas dos demais alunos, demandando a utilização de linguagens e códigos aplicáveis;

III - altas habilidades/superdotação, grande facilidade de aprendizagem que os leve a dominar rapidamente conceitos, procedimentos e atitudes. (BRASIL, 2001a).

E, no Art. 7o, da mesma Resolução, explicita que "[...] o atendimento aos alunos com necessidades educacionais especiais deve ser realizado em classes comuns do ensino regular, em qualquer etapa ou modalidade da Educação Básica" (BRASIL, 2001). Ainda, em 2001, foi promulgado o Decreto no 3.956/2001, como ato de adesão à Convenção Interamericana para a Eliminação de Todas as Formas de Discriminação contra as Pessoas Portadoras de Deficiência, realizada na Guatemala, em 1999. Buscava reafirmar para as pessoas com deficiência "[...] os mesmos direitos humanos e liberdades fundamentais que outras pessoas e que estes direitos, inclusive o direito de não ser submetidas a discriminação com base na deficiência, emanam 
da dignidade e da igualdade que são inerentes a todo ser humano" (BRASIL, 2001, s.p.), para com isso, "[...] prevenir e eliminar todas as formas de discriminação contra as pessoas portadoras de deficiência e propiciar a sua plena integração à sociedade" (BRASIL, 2001a, s.p.).

Ainda em 2001, outra legislação importante para a Educação Especial foi o Plano Nacional de Educação (2001-2010), aprovado pela Lei no 10.172/2001, o qual estabeleceu diretrizes Nacionais para a Educação Especial na Educação Básica (2001), uma vez que estabeleceu, como uma das diretrizes da área educacional, a plena integração de pessoas com necessidades especiais em todas as áreas da sociedade, tratando, portanto, do "[...] direito à educação, comum a todas as pessoas, e o direito de receber essa educação sempre que possível junto com as demais pessoas nas escolas regulares" (BRASIL, 2001b, p. 120). Seguindo o rumo das políticas educacionais apresentadas após a Reforma do Estado (1995), o PNE (2001) deu ênfase aos convênios entre o Estado e empresas privadas, organizações civis e/ ou não governamentais para o atendimento educacional especializado aos alunos com deficiência, configurando-se, assim, o desempenho das funções estatais a respeito das políticas educacionais.

Esses fatos, por um lado, são coetâneos com a inclusão do país no novo panorama econômico mundial, percebida tanto como condição, como resultado nas discussões sobre a realização das metas de construção da democracia, do acesso à cidadania e do desenvolvimento da nação, sinalizando para a redefinição do papel do Estado (BIGARELLA, 2004). Dessa maneira, ainda conforme Bigarella (2004), concretizaram-se as relações que se estabeleceram entre a concepção de Estado o modelo de amparo social.

Após 2003, de acordo com Machado e Vernick (2013), a preocupação foi com o acesso à educação, a permanência e as condições de aprendizagem dos alunos com deficiência. Para tanto foi elaborado o documento: O Acesso de Alunos com Deficiência às Escolas e Classes 
Comuns da Rede Regular (2004), organizado pela Procuradoria Federal dos Direitos do Cidadão, com a ajuda de professores das escolas públicas de Brasília, publicado pelo Ministério Público Federal, no ano de 2004. Tinha como objetivo "[...] divulgar os conceitos mais atuais e adequados às diretrizes mundiais de inclusão da pessoa com deficiência na área educacional" (BRASIL, 2004, p. 5) para, assim, excluir da sociedade os preconceitos e as práticas que segregam as pessoas com deficiência, "[...] que vão desde as discriminações negativas, até uma bem-intencionada reprovação de uma série para outra" (BRASIL, 2004, p. 5). A ideia principal que o documento pretende divulgar é que é possível criar "[...] uma escola que permita a convivência com essa consciência da diversidade [...]", possibilitando assim, "[...] um preparo para a cidadania e um desenvolvimento humano muito maior para todos" (BRASIL, 2004, p. 51).

No ano de 2006, outro evento importante para as políticas de educação especial foi a Convenção Internacional sobre os Direitos das Pessoas com Deficiência, ocorrido em Bengala, na Índia. Dessa Convenção, saiu a Resolução A/61/611, aprovada pela Assembleia Geral da Organização das Nações Unidas (ONU), com o objetivo de "[...] promover, proteger e garantir o pleno e igual gozo de todos os direitos humanos e liberdades fundamentais por todas as pessoas com deficiência e promover o respeito pela sua dignidade inerente" (ONU, 2006, p. 3).

Para tanto, conforme expresso, o documento, reafirmou à pessoa com deficiência o direito a "[...] acessibilidade ao ambiente físico, social, econômico e cultural, à saúde e educação e a informação e comunicação, ao permitir às pessoas com deficiência o pleno gozo de todos os direitos humanos e liberdades fundamentais" (ONU, 2006, p. 2). Reconheceu a importância de formulação de políticas educacionais em níveis nacional e regional, que tenham como princípio a não discriminação, a "[...] autonomia individual e o respeito pela diferença 
e aceitação das pessoas com deficiência como parte da diversidade humana e humanidade" (ONU, 2006, p. 2). Por meio do Decreto 186/2008, o Estado brasileiro tornou-se signatário, encorpando os princípios dessa Convenção Internacional à sua política educacional.

Em 2007, a Secretaria Especial de Direitos Humanos (SEDH), em conjunto com os Ministérios da Educação (MEC) e Ministério da Justiça (MJ), elaborou o Plano Nacional de Educação em Direitos Humanos (PNEDH, 2007), que incorporou, de acordo com o documento

[...] aspectos dos principais documentos internacionais de direitos humanos dos quais o Brasil é signatário, agregando demandas antigas e contemporâneas de nossa sociedade pela efetivação da democracia, do desenvolvimento, da justiça social e pela construção de uma cultura de paz. (BRASIL, 2007a, p. 11).

Na seção da Educação Básica: concepções e princípios, de acordo o PNEDH (2007), a educação em direitos humanos precisa envolver questões concernentes à escola (educação formal); "[...] aos procedimentos pedagógicos, às agendas e instrumentos que possibilitem uma ação pedagógica conscientizadora e libertadora, voltada para o respeito e valorização da diversidade, aos conceitos de sustentabilidade e de formação da cidadania ativa" (BRASIL, 2007b, p. 32).

Nesse mesmo documento, dentre as 26 ações programáticas para efetivação dos direitos humanos na educação básica, as ações 9 e 10 tratam da universalização das questões da diversidade, das pessoas com deficiência e exclusão social, como importante condição desencadeadora de um processo de mudança no comportamento social, para o desenvolvimento de uma outra "[...] cultura de direitos humanos em todos os espaços sociais" (BRASIL, 2007a, p. 32), conforme explicita o documento:

9. fomentar a inclusão, no currículo escolar, das temáticas relativas a gênero, identidade de gênero, raça e etnia, religião, orientação sexual, pessoas com deficiências, entre outros, bem 
como todas as formas de discriminação e violações de direitos, assegurando a formação continuada dos (as) trabalhadores (as) da educação para lidar criticamente com esses temas;

10. apoiar a implementação de projetos culturais e educativos de enfrentamento a todas as formas de discriminação e violações de direitos no ambiente escolar. (BRASIL, 2007b, p. 33).

A busca pela efetividade da proteção dos direitos proclamados pela Constituição Federal de 1988 condiz com o processo de democratização do país, ainda em andamento e com o que instituiu o seu art. 205, Inciso VI, a "gestão democrática do ensino público, na forma da lei, como um dos princípios do ensino" (BRASIL, 1988), e a LDBEN 9.394/1996, que confirmou esse princípio no art. $3^{\circ}$, Inciso VIII, "[...] gestão democrática do ensino público, na forma desta Lei e da legislação dos sistemas de ensino" (BRASIL, 1996). O exercício democrático é condição necessária para a educação se concretizar como direito universal; além do seu reconhecimento jurídico, precisará vir "[...] acompanhado da vontade política dos poderes públicos no sentido de torná-lo efetivo e da capacidade de a sociedade civil organizar-se e mobilizar-se para exigir o seu atendimento [...]" (HORTA, 1998, p. 10).

Em 2009, a Resolução no 4/2009, do Conselho Nacional de Educação, que instituiu as "Diretrizes Operacionais para o Atendimento Educacional Especializado na Educação Básica, modalidade Educação Especial" (BRASIL, 2009, p. 1), resolveu no seu Art. 1ㅇqu "[...] os sistemas de ensino [deveriam] matricular os alunos com deficiência, transtornos globais do desenvolvimento e altas habilidades/superdotação nas classes comuns do ensino regular [...]", bem como, em "[...] centros de Atendimento Educacional Especializado (AEE) da rede pública ou de instituições comunitárias, confessionais ou filantrópicas sem fins lucrativos", que possuam salas de recursos multifuncionais (BRASIL, 2009, p. 1). 
Em 2011, o Decreto № 7.690/2012, que aprovou a reestruturação na estrutura regimental e o Quadro Demonstrativo dos Cargos em Comissão e das Funções Gratificadas do Ministério da Educação, organizou-o em 5 diretorias: Políticas de Educação do Campo, Indígena e para Relações Étnico-Raciais; Políticas de Alfabetização e Educação de Jovens e Adultos; Políticas de Educação em Direitos Humanos e Educação; Políticas de Educação Especial; e Políticas de Educação para a Juventude (BRASIL, 2012).

Essa organização do MEC, para Bezerra e Araújo (2014), trouxe discretas alterações na composição da Secretaria de Educação Continuada, Alfabetização, Diversidade e Inclusão (SECADI), que substitui a então Secretaria de Educação Continuada, Alfabetização e Diversidade (SECAD), pois manteve a estrutura e função da antiga secretaria, porém ampliadas, pois passou a ter outras políticas sob sua responsabilidade. Nesse período, as ações do SECADI voltaram-se para a "[...] valorização das diferenças e da diversidade, à promoção da educação inclusiva, dos direitos humanos e da sustentabilidade socioambiental, visando à efetivação de políticas públicas transversais e intersetoriais" (BRASIL, 2012, s.p.).

Com relação especificamente à educação especial, nesse período, foi dado ênfase a dois programas: o Programa Implantação de Salas de Recursos Multifuncionais, criado em 2007, pela Portaria Normativa no 13, de 24 de abril de 2007, com o objetivo de "[...] apoiar os sistemas públicos de ensino na organização e oferta do atendimento educacional especializado e contribuir para o fortalecimento do processo de inclusão educacional nas classes comuns de ensino" (BRASIL, 2007b, s.p.). E o Programa de Formação Continuada de Professores em Educação Especial, criado pela Portaria no 1.086, de agosto de 2011, com o objetivo, conforme expressa o Art. 1ํㅡ, de

Instituir o Grupo de Trabalho com a atribuição de acompanhar e assessorar o Grupo de Apoio Pedagógico- GAP no desenvol- 
vimento das atividades pedagógicas relacionadas à implementação do Programa Educação Financeira nas Escolas, no âmbito da Estratégia Nacional de Educação Financeira e Previdenciária -ENEF, instituída pelo Decreto № 7.397/2010, de 23/12/2010. (BRASIL, 2011, p. 1).

Na análise de Dias (2011, p. 59), no âmbito da Educação Especial, essas ações podem ser consideradas "[...] uma grande conquista para os alunos com deficiência uma vez que o Estado assumiu os custos do AEE complementar ou suplementar e reconheceu o direito à diferença como direito à equiparação de oportunidades".

Em 2013, a Resolução/CD/FNDE no 19, de 21 de maio de 2013, visava "[...] assegurar o direito à educação e promover autonomia e independência das pessoas com deficiência, transtornos globais do desenvolvimento e altas habilidades/superdotação no contexto escolar" (BRASIL, p. 2003a, p. 1), por meio de reorganização nos prédios escolares, que assegurassem "[...] aos estudantes da educação especial, matrícula nas classes comuns e oferta do atendimento educacional especializado, previsto no projeto político pedagógico da escola" (BRASIL, 2013a, p. 1). Para tanto, foi elaborado o Documento Orientador do Programa Escola Acessível (2013), que objetiva orientar os sistemas de ensino na implementação do Programa Escola Acessível, ação integrante do eixo acesso à educação, do Plano Nacional dos Direitos da Pessoa com Deficiência - Viver sem Limite (BRASIL, 2013b, p. 3).

Em 2014, a Lei no 13.005/2014 aprovou o Plano Nacional de Educação (PNE), conceituado como "[...] um instrumento de planejamento do nosso Estado democrático de direito que orienta a execução e o aprimoramento de políticas públicas do setor", o documento apresenta os "[...] objetivos e metas para o ensino em todos os níveis - infantil, básico e superior - a serem executados nos próximos dez anos" (BRASIL, 2014a, p. 7) 
Na elaboração desse PNE (2014-2024), conforme apresenta o documento "Planejando a Próxima Década Conhecendo as 20 Metas do Plano Nacional de Educação", foi fundamental "[...] incorporar os princípios do respeito aos direitos humanos, à sustentabilidade socioambiental, à valorização da diversidade e da inclusão e à valorização dos profissionais que atuam na educação de milhares de pessoas todos os dias" (BRASIL, 2014b, p. 9), uma vez que a elaboração de um plano de educação precisa ter como fundamento "[...] metas estruturantes para a garantia do direito à educação básica com qualidade, que dizem respeito ao acesso, à universalização da alfabetização e à ampliação da escolaridade e das oportunidades educacionais" (BRASIL, 2014b, p. 9), tais como:

Meta 1: universalizar, até 2016, a educação infantil na pré-escola para as crianças de 4 (quatro) a 5 (cinco) anos de idade e ampliar a oferta de educação infantil em creches, de forma a atender, no mínimo, 50\% (cinquenta por cento) das crianças de até 3 (três) anos até o final da vigência deste PNE.

Meta 2: universalizar o ensino fundamental de 9 (nove) anos para toda a população de 6 (seis) a 14 (quatorze) anos e garantir que pelo menos 95\% (noventa e cinco por cento) dos alunos concluam essa etapa na idade recomendada, até o último ano de vigência deste PNE.

Meta 3: universalizar, até 2016, o atendimento escolar para toda a população de 15 (quinze) a 17 (dezessete) anos e elevar, até o final do período de vigência deste PNE, a taxa líquida de matrículas no ensino médio para $85 \%$ (oitenta e cinco por cento).

Meta 5: alfabetizar todas as crianças, no máximo, até o final do 3 o (terceiro) ano de ensino fundamental.

Meta 6: oferecer educação em tempo integral em, no mínimo, $50 \%$ (cinquenta por cento) das escolas públicas, de forma a atender, pelo menos, 25\% (vinte e cinco por cento) dos(as) alunos(as) da educação básica. 
Meta 7: fomentar a qualidade da educação básica em todas as etapas e modalidades, com melhoria do fluxo escolar e da aprendizagem, de modo a atingir as seguintes médias nacionais para o Ideb: 6,0 nos anos iniciais do ensino fundamental; 5,5 nos anos finais do ensino fundamental; 5,2 no ensino médio.

Meta 9: elevar a taxa de alfabetização da população com 15 (quinze) anos ou mais para 93,5\% (noventa e três inteiros e cinco décimos por cento) até 2015 e, até o final da vigência deste PNE, erradicar o analfabetismo absoluto e reduzir em $50 \%$ (cinquenta por cento) a taxa de analfabetismo funcional.

Meta 10: oferecer, no mínimo, 25\% (vinte e cinco por cento) das matrículas de educação de jovens e adultos, nos ensinos fundamental e médio, na forma integrada à educação profissional.

Meta 11: triplicar as matrículas da educação profissional técnica de nível médio, assegurando a qualidade da oferta e pelo menos 50\% (cinquenta por cento) da expansão no segmento público. (BRASIL, 2014b, p. 9-10).

Outras metas dizem respeito especificamente à "[...] redução das desigualdades e à valorização da diversidade, caminhos imprescindíveis para a equidade" (BRASIL, 2014b, p. 11), conforme apresentam as duas que se seguem:

Meta 4: universalizar, para a população de 4 (quatro) a 17 (dezessete) anos com deficiência, transtornos globais do desenvolvimento e altas habilidades ou superdotação, o acesso à educação básica e ao atendimento educacional especializado, preferencialmente na rede regular de ensino, com a garantia de sistema educacional inclusivo, de salas de recursos multifuncionais, classes, escolas ou serviços especializados, públicos ou conveniados.

Meta 8: elevar a escolaridade média da população de 18 (dezoito) a 29 (vinte e nove) anos, de modo a alcançar, no mínimo, 12 (doze) anos de estudo no último ano de vigência deste plano, para as populações do campo, da região de menor escolaridade no País e dos 25\% (vinte e cinco por cento) mais 
pobres, e igualar a escolaridade média entre negros e não negros declarados à Fundação Instituto Brasileiro de Geografia e Estatística - IBGE. (BRASIL, 2014b, p. 11).

O Educação como um dos Direitos Humanos e a universalização do atendimento escolar a todos, incluindo o público da educação especial, atende ao compromisso assumido pelo Brasil na Conferência Mundial de Educação para Todos (1990), na Convenção Internacional sobre os Direitos das Pessoas com Deficiência (2006), na Convenção sobre os Direitos das Pessoas com Deficiência (ONU, 2006), no Plano Nacional de Educação em Direitos Humanos (2007), bem como em outras ações expressas nos documentos acima citados.

Faz-se necessário esclarecer que o PNE (2014-2024) contextualiza 20 metas e mostra as "[...] suas inter-relações com a política pública mais ampla, e um quadro com sugestões para aprofundamento da temática" (BRASIL, 2014b, p. 6), em blocos que tratam do direito à educação, outras diversidades e desigualdades, conforme já foi abordado anteriormente e, outras metas que tratam da valorização dos profissionais da educação e, ainda, que se referem ao ensino superior, que não são objetos de estudos desta pesquisa.

A Educação como Direito Humano, direito de todos, muito embora esteja garantida na forma da lei, não é considerada de caráter absoluto, acontece de forma peculiar, conforme as condições estruturais e conjunturais de uma sociedade. Conforme explica Bobbio (1992, p. 10), “[...] uma coisa é proclamar esse direito, outra é desfrutá-lo efetivamente". Continua o autor:

A linguagem dos direitos tem indubitavelmente uma grande função prática, que é emprestar uma força particular às reivindicações dos movimentos que demandam para si e para os outros a satisfação de novos carecimentos materiais e morais; mas ela se torna enganadora se obscurecer ou ocultar a diferença entre o direito reivindicado e o direito reconhecido e protegido. (BOBBIO, 1992, p. 10). 
Assim, aceitando essa análise de que as garantias constitucionais não possuem caráter absoluto, a Decisão Julgada (DJ 12/05/2000), do Supremo Tribunal Federal, proferida pelo Ministro Celso de Mello (DJ 12/05/00), explica que a efetividade desses direitos não dependem somente da elaboração da lei, dependem de outras razões, interesses e/ou da adoção, por parte dos órgãos estatais, de medidas que façam valer as "[...] prerrogativas individuais ou coletivas, desde que respeitados os termos estabelecidos pela própria Constituição" (BRASIL, STJ, DJ 12/05/00).

\section{CONSIDERAÇÕES FINAIS}

Com base na discussão e documentos apresentados, observamos que os direitos humanos são parte importante no processo educativo, pois agencia a aceitação da diversidade, da solidariedade e o fortalece a ideia da inclusão das pessoas com deficiência no ensino regular, ou seja, matriculadas, respectivamente, no ensino regular e no Atendimento Educacional Especializado, conforme prescreve o art. 208, III, da Constituição Federal de 1988.

A educação tem por objetivo preparar para o exercício da cidadania. Essa preparação envolve o sentimento de pertencimento e/ou inclusão em uma sociedade formada pela diversidade humana; logo, não pode haver separação das pessoas com ou sem deficiências. Isso implica o dever do Estado em garantir os direitos fundamentais de todos, dentre os quais o direito à educação. Para isso, é importante que a escola atue como articuladora da diversidade social e dos interesses da sociedade, atendendo a todos, valorizando as diferenças humanas e salvaguardando os direitos de todos, como condição imprescindível para a democracia, pois é na escola que acontece a participação dos diferentes segmentos sociais. 


\section{REFERÊNCIAS}

BIGARELLA, N. Materialização da política de municipalização do ensino fundamental de Mato Grosso do Sul nos anos 1993 a 2002. 2004. Dissertação (Mestrado e Educação) - Universidade Federal de Mato Grosso do Sul, Campo Grande, MS, 2004.

BIGARELLA, N. O papel do Conselho Estadual de Educação de Mato Grosso do Sul na definição de políticas para a gestão da educação básica (19992014). 2015. Tese (Doutorado em Educação) - Universidade Católica Dom Bosco, Campo Grande, MS, 2015.

BOBBIO, N. A era dos direitos. Tradução de Carlos Nelson Coutinho. Rio de Janeiro: Campus, 1992.

BRASIL. Lei n. 13.005, de 25 de junho de 2014. Aprova o Plano Nacional de Educação- PNE e dá outras providências. Brasília, 25 de junho de 2014a.

BRASIL. Ministério da Educação. Plano Nacional de Educação 2014-2024. Brasília, 2014b

BRASIL. Resolução/CD/FNDE n. 19, de 21 de maio de 2013. Dispõe sobre a destinação de recursos financeiros, nos moldes operacionais e regulamentares do Programa Dinheiro Direto na Escola (PDDE), a escolas públicas municipais, estaduais e do Distrito Federal da educação básica, com matrículas de alunos público alvo da educação especial em classes comuns do ensino regular, que tenham sido contempladas com salas de recursos multifuncionais. Brasília: Ministério da Educação, 2013a.

BRASIL. Secretaria de Educação Especial. Programa Escola Acessível. Documento Orientador do Programa Escola Acessível. Brasília: Ministério da Educação. 2013b.

BRASIL. Lei n. 12.796/2013. Altera a Lei n. 9.394, de 20 de dezembro de 1996, que estabelece as diretrizes e bases da educação nacional, para dispor sobre a formação dos profissionais da educação e dar outras providências. Brasília, 4 de abril de 2013c .

BRASIL. Secretaria de Direitos Humanos da Presidência da República. Educação em Direitos Humanos: Diretrizes Nacionais. Brasília: Coordenação Geral de Educação em SDH/PR; Direitos Humanos; Secretaria Nacional de Promoção e Defesa dos Direitos Humanos, $2013 d$. 
A Educação Especial como um dos direitos humanos: contextualização fática das políticas educacionais

BRASIL, Ministério da Educação. Parecer CNE/CP n. 8/2012, aprovado em 6 de março de 2012. Diretrizes Nacionais para a Educação em Direitos Humanos. Disponível em: <http://portal.mec.gov.br>. Acesso em: 23 abr. 2016.

BRASIL. Secretaria Especial de Direitos Humanos. Plano Nacional de Educação em Direitos Humanos. Brasília: Ministério da Educação, 2007a. Disponível em: <http://www.sdh.gov.br>. Acesso em: 23 abr. 2016.

BRASIL. Plano Nacional de Educação em Direitos Humanos: 2007. Comitê Nacional de Educação em Direitos Humanos. Brasília: Secretaria Especial dos Direitos Humanos; Ministério da Educação; Ministério da Justiça; UNESCO, 2007b.

BRASIL. Ministério Público Federal; Fundação Procurador Pedro Jorge de Melo e Silva (Org.). O acesso de alunos com deficiência às escolas e classes comuns da rede regular. 2. ed. rev. e atualiz. Brasília: Procuradoria Federal dos Direitos do Cidadão, 2004.

BRASIL. Ministério da Educação. Diretrizes nacionais da educação especial na educação básica. Brasília: Secretaria de Educação Especial; MEC/SEESP, 2001.

BRASIL. Superior Tribunal de Justiça. MS 23452 RJ. PP-00020 EMENT VOL01990-01 PP-00086. Decisão Julgada pelo Ministro Celso de Mello, 12 de maio de 2000. Disponível em: <http://www.stf.jus.br/portal/jurisprudencia/ visualizarEmenta.asp?s1=000020700\&base=baseAcordaos $>$. Acesso em: 26 maio 2016.

BRASIL. Lei n. 9.394, de 20 de dezembro de 1996. Estabelece as Diretrizes e Bases da Educação Nacional. Brasília,1996.

BRASIL. Ministério da Educação. Secretaria de Educação Especial. Política Nacional de Educação Especial: livro 1. Brasília: MEC/SEESP, 1994.

BRASIL. Constituição Federal de 1988. Disponível em: <http://www. planalto. gov.br/ccivil_03/constituicao/ConstituicaoCompilado>. Acesso em: 23 abr. 2016.

BRASIL. Constituição Federal de 24 de janeiro de 1967. Disponível em: <www. planalto.gov.br>. Acesso em: 23 abr. 2016.

BRASIL. Ministério da Marinha de Guerra, Ministério do Exercício e da Aeronáutica. Emenda Constitucional n. 1, de 17 de outubro de 1969. Constituição Federal de 1967. Disponível em: <www. planalto.gov.br>. Acesso em: 23 abr. 2016. 
BRASIL. Lei n. 4.024, de 20 de dezembro de 1961. Fixa as Diretrizes e Bases da Educação Nacional. Brasília: Congresso Nacional, 1961.

BRASIL. Constituição dos Estados Unidos do Brasil (de 18 de setembro de 1946). Brasília: Palácio do Planalto, 1946. Disponível em: <http://www. planalto.gov.br/ccivil_03/Constituicao/Constituicao46.htm>. Acesso em: 21 abri. 2016.

BRASIL. Constituição da República dos Estados Unidos do Brasil (de 24 de fevereiro de 1891). Brasília: Palácio do Planalto, 1891. Disponível em: <http:// www.planalto.gov.br/ccivil_03/Constituicao/Constituicao91.htm>. Acesso em: 3 de maio de 2016.

BRASIL. Constituição Politica do Imperio do Brazil (de 25 de março de 1824). Brasília: Palácio do Planalto, 1824. Disponível em: <http://www.planalto. gov.br/ccivil_03/Constituicao/Constituicao24.htm>. Acessado em: 2 de abril de 2016.

GARCIA, Rosalba Maria Cardoso; MICHELS, Maria Helena. A política de educação especial no Brasil (1991-2011): uma análise da produção do GT15 - educação especial da ANPED. Rev. Bras. Educ. Espec., Marília, v. 17, número especial, maio/ago. 2011.

HOBSBAWM, Eric. Era dos extremos: o breve século XX (1914-1991). São Paulo: Companhia das Letras, 1995.

HORTA, José Silverio Baia. Direito à educação e obrigatoriedade escolar. Cadernos de Pesquisa - Fundação Carlos Chagas, São Paulo, n. 104, p. 5-34, 1998.

IANNI, Octavio. A era do globalismo. 3. ed. Rio de Janeiro: Civilização Brasileira, 1997.

KASSAR, Mônica de Carvalho Magalhães. Educação especial na perspectiva da educação inclusiva: desafios da implantação de uma política nacional. Educar em Revista, Curitiba, n. 41, p. 61-79, jul./set. 2011.

MACHADO, Evelcy Monteiro; VERNICK, Maria da Glória Lima Pereira. Reflexões sobre a política de Educação Especial e no Paraná. Nuances: estudos sobre Educação, Presidente Prudente, SP, v. 24, n. 2, p. 49-67, maio/ago. 2013.

MATO GROSSO DO SUL, Estado [de] . Lei n. 4.621, de 22 de dezembro de 2014. Aprova o Plano Estadual de Educação de Mato Grosso do Sul, e dá outras providências. Campo Grande, 2014a. 
MATO GROSSO DO SUL, Estado [de]. Secretaria de Estado de Educação de Mato Grosso do Sul. PEE/MS: Plano Estadual de Educação (2014-2024) de Mato Grosso do Sul. Campo Grande, MS: SED, 2014b.

MÉSZÁROS, István. A educação para além do capital. São Paulo: Boitempo, 2008.

MICHELS, Lísia Regina Ferreira. A inclusão/exclusão da pessoa portadora de necessidades especiais no contexto universitário. 2000. 107 p. Dissertação (Mestrado em Psicologia Social e da Personalidade) - Pontifícia Universidade Católica do Rio Grande do Sul (PUCRS), Porto Alegre, RS, 2000.

ORGANIZAÇÃO DAS NAÇÕES UNIDAS (ONU). Convenção sobre os Direitos das Pessoas com Deficiência. Protocolo aprovado juntamente com a Convenção sobre Direitos das Pessoas com Deficiência, pela Assembleia Geral das Nações Unidas, no dia 6 de dezembro de 2006, através da resolução A/61/611. Disponível em: <http://www.bengalalegal.com/convencao>. Acesso em: 25 maio 2016.

SARLET, Ingo Wolfgang. A eficácia dos Direitos Fundamentais. 9. ed. Porto Alegre: Editora Livraria do Advogado, 2007.

SASSAKI, Romeu Kazumi. Como chamar as pessoas que têm deficiência? Revista da Sociedade Brasileira de Ostomizados, ano I, n. 1, 1ㅇs. sem. 2003, p. 8-11.

SAVIANI, D. Escola e democracia. 31. ed. Campinas: Autores Associados, 1997. (Polêmicas do Nosso Tempo, v. 5). 
